\title{
PORRESPONDENCE
}

\section{The Screening, Diagnosis, Treatment, and Follow-Up of Breast Cancer}

by Prof. Dr. med. Achim Wöckel, Prof. Dr. med. Ute-Susann Albert, Prof. Dr. med. Wolfgang Janni, Prof. Dr. med. Anton Scharl, Prof. Dr. med. Rolf Kreienberg, and Dr. med. Tanja Stüber in issue 18/2018

\section{The Result is a Zero-Sum Game}

"The value of mammographic screening is confirmed in the updated guideline," write the authors (1). Later, however, they state that evidence for the reduction of breast cancer mortality due to the screening is highly inhomogeneous. Notwithstanding this, participation in the German Mammography Screening Programme is recommended.

A reduction in breast cancer mortality through participation in the screening was "also" demonstrated for women between the ages of 40 and 49 , although unfortunately no absolute risk reduction was given. Screening healthy women between the ages of 50 and 69 could save up to eight out of every 1000 women from dying from breast cancer over the next 20 years (10 screening rounds). However, this figure clearly contradicts the results of the Nordic Cochrane Center (2).

Unfortunately, nothing is said about all-cause mortality in women. Taking all-cause mortality of women into consideration, the result is a zero-sum game (3).

Evidence for a reduction in breast cancer mortality is currently insufficient for other imaging tests and is very inhomogeneous for mammography, but apparently this is enough for mammography to be recommended. One can remain skeptical. Figure 1 in the article (showing the relative five-year survival versus tumor stage) suggests that early detection is beneficial, yet says nothing about mortality. Tumor biology remains decisive. Rather than the S3 guidelines recommending participation in screening, one should consider how to get out of a program based on "inhomogeneous evidence" and invest money in basic research instead. DOI: $10.3238 / a r z t e b l .2019 .0009 a$

\section{References}

1. Wöckel A, Albert US, Janni W, Scharl A, Kreienberg R, Stüber T: Clinical practice guideline: The screening, diagnosis, treatment, and follow-up of breast cancer. Dtsch Arztebl Int 2018; 115: 316-23.

2. Gøtzsche PC, Hartling OJ, Nielsen M, Brodersen J: Screening for breast cancer with mammography. The Nordic Cochrane Center 2012. www.nordic.cochrane.org/sites/ nordic.cochrane.org/files/public/uploads/images/mammography/mammographyleaflet.pdf (last accessed on 27 June 2018).

3. Biller-Andorno N, Jüni P: Abolishing mammography screening programs? A view from the Swiss Medical Board. N Engl J Med. 2014; 370: 1965-7.

\section{Peter Bußmann}

Facharzt für Geburtshilfe und Frauenheilkunde, Ense

\section{Conflict of interest statement}

The author declares that no conflict of interest exists.

\section{Rationally Incomprehensible}

The recommendations published in this article (1) are not rationally comprehensible - with considerable consequences for the women affected:

- The authors claim that "by screening women aged between 50 and 69 years (approximately 10 rounds), up to eight lives can be saved out of 1000 currently healthy participants," and that "the rate of follow-up visits for repeat imaging of what ultimately proves to be a benign finding is around 2\% in Europe." However, the most recent meta-analysis (2) cited by the authors (1) describes a breast cancer-specific mortality reduction of 12.5 from 10000 (!) women. The cumulative rates for false-positive mammography findings during ten years were between $42 \%$ and $61 \%$, and the estimates of overdiagnosis, between $11 \%$ and $22 \%$. - Postoperative radiotherapy of the regional lymph nodes significantly reduces the risk of relapse (especially for distant metastases), if axillary lymph node involvement was primarily diagnosed (3). But how is it supposed to be reliably diagnosed if this measure is taken after neoadjuvant chemotherapy? How should location and number of affected regional lymph nodes be differentiated if only a sentinel node biopsy was performed?

DOI: 10.3238/arztebl.2019.0009b

\section{References}

1. Wöckel A, Albert US, Janni W, Scharl A, Kreienberg R, Stüber T: Clinical practice guideline: The screening, diagnosis, treatment, and follow-up of breast cancer. Dtsch Arztebl Int 2018; 115: 316-23.

2. Nelson HD, Pappas M, Cantot A, Griffin J, Daeges M, Humphrey L: Harms of breast cancer screening: systematic review to update the 2009 U.S. preventive services task force recommendation. Ann Intern Med 2016; 164: 256-67.

3. Budach W, Kammers K, Boelke E, Matuschek C: Adjuvant radiotherapy of regional lymph nodes in breast cancer-a meta-analysis of randomized trials. Radiat Oncol 2013; 8: 267.

Prof. Dr. rer. nat. Dr. med. Dipl. math. Clemens F. Hess

Klinik für Strahlentherapie und Radioonkologie

der Universitätsmedizin Göttingen

cfhess@med.uni-goettingen.de

Conflict of interest statement

The author declares that no conflict of interest exists.

\section{Below the Biologically Effective Dose}

As regular readers of the Deutsches Ärzteblatt, we first came across the presentation of the S3 guideline mentioned in the article (1) a few months ago online. Already at that time, we noticed that in the section on breast radiotherapy after breastconserving surgery, finally the moderately hypofractionated radiation, of about 40 Gy in 15 to 16 fractions, was listed, but within a period of 3 to 5 weeks (according to Evidence-based Recommendation 4.37; only the following text [page 143] correctly states "to combine with moderate acceleration [3 weeks]").

The stated duration of "up to 5 weeks" seems to be a central mistake. It cannot be ruled out that with such a time regimen and at the indicated dosage, the biologically effective dose of 25 fractions of 2 Gy over 5 weeks would be insufficient due to accelerated repopulation (which occurs on average about three weeks after the start of radiation and is "compensated" on average by about $0.65-0.7$ Gy per day). This can also be seen in the section of the START trials that compared $13 \times 3$ Gy over 5 
weeks with $25 \times 2$ Gy over 5 weeks (2-4). Apparently, for the biological effective dose calculations in this arm of the START-A trial, the decision was made to maintain the same total time of irradiation in the two arms.

Incidentally: after many decades of clinical experience with moderately hypofractionated radiation for this indication, the randomized comparisons and their results could have been obtained much earlier, which would have saved a lot of money.

DOI: $10.3238 / a r z t e b l .2019 .0009 c$

\section{References}

1. Wöckel A, Albert US, Janni W, Scharl A, Kreienberg R, Stüber T: Clinical practice guideline: The screening, diagnosis, treatment, and follow-up of breast cancer. Dtsch Arztebl Int 2018; 115: 316-23.

2. Haviland JS, Owen JR, Dewar JA, et al.: The UK Standardisation of Breast Radiotherapy (START) trials of radiotherapy hypofractionation for treatment of early breast cancer: 10-year follow up results of two randomised trials. Lancet Oncol 2013; 14: 1086-94.

3. Owen JR, Ashton A, Bliss JM, et al: Effect of radiotherapy fraction size on tumour control in patients with early-stage breast cancer after local tumour excision: long term results of a randomised trial. Lancet Oncol 2006; 7: 467-71.

4. Haviland JS, Bentzen SM, Bliss JM, Yarnold JR: Prolongation of overall treatment time as a cause of treatment failure in early breast cancer: an analysis of the UK START (Standardisation of Breast Radiotheraoy) trials of radiotherapy fractionation. Radiother Oncol 2016; 121: 420-3.

Prof. Dr. med. Christoph Glanzmann

Prof. Dr. med. Gabriela Studer

Luzerner Kantonsspital

christoph.glanzmann@luks.ch

\section{Conflict of interest statement}

The authors declares that no conflict of interest exists.

\section{In Reply:}

We are grateful for the contributions to the discussion, which we will briefly address. We would recommend that all interested parties refer to the long version of the $\mathrm{S} 3$ guideline, which has a detailed explanation of the complex evidence situation.

Mammography screening: The updated German S3 guideline has taken into account the recommendations of the American Cancer Society (1), the US Preventive Task Force (2), and the International Agency for Research on Cancer (IARC) (3). The IARC confirms the results of the meta-analyses of existing randomized controlled trials (RCTs) but considers wellcontrolled recent observational studies (approximately 20 incidence-based cohort and case-control studies) as more appropriate for the assessment of current screening programs.

The Cochrane analysis is based on data from older RCTs and calculates the effectiveness over a ten-year period after five rounds of screening. However, calculating screening effectiveness requires a longer observation period to exclude the length-time bias. These requirements are met by the incidencebased cohort studies. Different final outcomes can be obtained depending on the cohorts - hence the reference to "inhomogeneous evidence."

For example, the numbers needed to screen (NNS) show the absolute effects in the different age groups: to prevent one death in the 40- to 49-year age group, the NNS is 1770 women assuming a $20 \%$ mortality reduction, or 753 women assuming a $40 \%$ mortality reduction. For the 50- to 59-year age group, the NNS is 1097 or 462 assuming a $20 \%$ or $40 \%$ mortality reduction, respectively, and for the 60 - to 69 -year age group, 835 or 355 women, respectively (4).

As a standard for the definition, assessment, and planning of medical services, determinants of disease clusters are used in set populations. Only using all-cause mortality (number of deaths in a given period/population size) is not helpful here. Rather, cause-specific mortality (number of deaths from a specified cause in a given period / population size) is required.

Irradiation of lymphatic drainage regions: The issue of postoperative radiotherapy of lymphatic drainage regions is complex, and the evidence is not clear. The long version of the S3 guideline explains the study situation and outlines the possible courses of action. A clinical and sonographic suspicion of lymph node involvement should be diagnostically verified before biopsy, and histopathologically verified before therapy recommendation. As part of the case report of a tumor board review, an individual recommendation for each individual patient for postoperative irradiation must be provided.

Hypofractionation: Theoretically, an influence on repopulation could indeed be expected. However, according to available studies, differences in the effects of adjuvant therapy on breast cancer at three weeks as compared to five weeks is small and not statistically significant. The guideline therefore does not describe a specific scheme but a framework. However, it can also be assumed, based on the guideline text for routine care, that the use of $40 \mathrm{~Gy}$ or $40.5 \mathrm{~Gy}$ in 15 fractions over three weeks will be favored.

DOI: $10.3238 /$ arztebl.2019.0010

\section{References}

1. Duke Evidence Synthesis Group: Systematic review of cancer screening literature for updating American Cancer Society breast cancer screening guidelines. 2014, Durham, North Carolina.

2. Nelson HD, Fu R, Cantor A, Pappas M, Daeges M, Humphrey L: Effectiveness of breast cancer screening: systematic review and meta-analysis to update the 2009 U.S. preventive task force recommendation. Ann Intern Med 2016, 164: 244-55.

3. Breast Cancer Screening. IARC Handbook of Cancer Prevention. IARC, 2016.

4. Oeffinger KC, Fontham ET, Etzioni R, et al.: Breast cancer screening for women at average risk: 2015 guideline update from the American Cancer Society. JAMA 2015 314: 1599-614

5. Wöckel A, Albert US, Janni W, Scharl A, Kreienberg R, Stüber T: Clinical practice guideline: The screening, diagnosis, treatment, and follow-up of breast cancer. Dtsch Arztebl Int 2018; 115: 316-23.

\section{Prof. Dr. med. Achim Wöckel}

Frauenklinik des Universitätsklinikums Würzburg woeckel_A@ukw.de

Prof. Dr. med. Ute-Susann Albert

Prof. Dr. med. Ingrid Schreer

Prof. Dr. med. Wilfried Budach

\section{Conflict of interest statement}

Prof. Wöckel has received consultancy fees and reimbursement of participation fees from Pfizer, Novartis, Roche, Amgen, Celgene, and Eisai, and speaking honoraria from Novartis, Pfizer, Roche, Amgen, and Celgene.

Prof. Albert has received honoraria for expertise activities from Medexo, consulting honoraria from Pfizer, and study support from the WSG Study Group for conducting clinical studies.

The remaining authors declare that no conflict of interest exists. 